\title{
Effects of blast loading on prestressed girder bridges
}

\author{
William F. Cofer*, Debra S. Matthews and David I. McLean \\ Department of Civil and Environmental Engineering, Washington State Transportation Center, Washington State \\ University, Pullman, WA, USA
}

Received 25 November 2009

Revised 15 June 2010

\begin{abstract}
Since the events of September 11th, increased attention has been given to the effects of blast loading on structures. Bridges are especially important due to their potentially critical role in the economy and for emergency response. Prestressed concrete highway bridges are very common, representing 11 percent of state bridges nationwide. Yet, very little is known about how prestressed concrete bridges respond to blast loading.

A finite element model of a precast, prestressed concrete girder was created and validated with two experimental blast tests. It was found that for an explosive event above or below the girder, numerical and empirical results were consistent.

The girder model was expanded to a four-girder, simple-span bridge model. Three different scenarios were examined at the midspan of the bridge: a blast between two girders above the deck, a blast centered on a girder above the deck, and a blast beneath the deck. The two load cases from above resulted in highly localized damage with the possibility for other sections of the bridge to be immediately reopened after the event. Results for the load case from below indicate that the slab will be heavily damaged but the girders will remain intact.
\end{abstract}

\section{Introduction}

Traditionally, blast resistant design strategies have been reserved for military and government buildings, or for consideration of accidental explosions in chemical facilities. However, with recent worldwide events, many engineers are now incorporating anti-terrorism measures into the design of a much wider variety of structures. Highway bridges require special consideration because the condition of transportation infrastructure can significantly affect the economy. The loss of a critical bridge could result in economic damage not only on a local level, but possibly on a national or global level.

Prestressed concrete girders are commonly used for highway bridges. In Washington, nearly 3000 of the stateowned bridges are of this construction type, representing nearly 40 percent of the bridges in the state [1]. Across the nation, approximately 11 percent of all highway bridges are supported with prestressed concrete girders. However, very little research has been done to evaluate the blast performance of prestressed concrete members or the bridges they support.

The overall goals of the work described here were (1) to develop and evaluate modeling techniques for simulating the behavior of precast, prestressed concrete girders subjected to blast loading and (2) to apply those techniques to characterize the blast response of typical bridges constructed of those girders.

\footnotetext{
*Corresponding author. E-mail: wcofer@wsu.edu.
} 


\section{Background}

Traditionally, little research on the blast resistance of structures has appeared in the open literature. However, work has been done [2-4] to develop new design procedures for bridges to assess and mitigate terrorism risks. Using specialized software to compute blast pressures and uncoupled single-degree-of-freedom (SDOF) dynamic analysis, a prestressed concrete, multiple-span bridge was analyzed. The authors concluded that bridge geometry and blast standoff and location significantly affect response. Explosions below the deck may result in more damage than directly above the deck due to the reflection of blast waves in confined spaces between girders or near abutments.

Ishikawa et al. [5-7] studied the performance of prestressed concrete beams when subjected to impact loading. Bonded and unbonded prestressed beams were tested experimentally and analytically. It was found that, while static loading resulted in failure of the compression concrete for both the bonded and unbonded specimens, the higher load rate induced by impact resulted in the breaking of the prestressed tendon.

Compared to prestressed concrete, reinforced concrete has received much more attention from researchers over the years. Magnusson and Hallgren [8] subjected 49 high-strength reinforced concrete beams to air blast loading. Their study revealed that concrete beams show an increased load capacity for blast loading relative to static loading. The failure mechanism also changed for some beams between static and dynamic loading. Whereas all of the beams subjected to static loading failed in flexure, some of the beams subjected to air blast loading failed in shear.

Several different methods have been used to model reinforced concrete beams subjected to blast loads. Van Wees and Weerheijm [9] found that finite element analysis resulted in a good match with empirical results as long as strain rate effects are incorporated for concrete. Although finite element modeling takes more time and effort over a simpler and quicker SDOF analysis, it ultimately yields far more accurate results. Incorporating an accurate material model is crucial, however.

Fang et al. [10] used Timoshenko beam models and reported that strain rate effects can have a significant impact on reinforced concrete beam capacities when subjected to blast loading. In contrast, Stevens and Krauthammer [11] found that the use of a rate-independent Continuum Damage/Plasticity material in a similar analysis was found to yield results matching empirical data.

\section{Finite element model of a precast, prestressed concrete girder}

The principal objective of this research was to accurately model the response and the damage in a prestressed concrete highway bridge when subjected to blast loading. To accurately consider the potentially important effects of the loss of prestressing in both the concrete and the tendons within the girders, a detailed three dimensional finite element model was used. All analyses were accomplished with the commercially available software system, ABAQUS [12]. To validate the structural model and the loading applied, two blast tests involving actual girder specimens were modeled. Details of the testing may be found in the report by Ertle et al. [13].

The girder section for the test specimens was a Colorado Department of Transportation section. The bulb-tee section measured 3 feet- 6 inches high with a 3 feet-7 inches wide top flange. Twenty 0.6-inch, grade 270 strands provided the prestressing for the girder, while other reinforcing steel was Grade 60. The concrete was designated as Class "S". Figure 1 shows a cross-section of the girder at midspan. A span of 68 feet-4 inches was used for the model and experiments.

A cut-away view of the girder model is shown in Fig. 2, displaying the concrete, the reinforcing steel, and the prestressing tendons. A typical concrete element at the location of the blast was approximately a 3-inch cube. ABAQUS/Standard was used to determine the initial state of equilibrium due to prestressing and self-weight. ABAQUS/Explicit was then used for all of the dynamic analyses. The model utilized 8-node continuum elements with reduced integration for the modeling of all concrete. Since hourglassing is a problem with this element, the built-in hourglass control was used. The reinforcing and the tendons were modeled with 2-node, 3-D stress and displacement truss elements. These were embedded within the concrete elements.

Since ABAQUS/Standard and ABAQUS/Explicit include established and proven material models, these were used for the analysis. ABAQUS' concrete damaged plasticity model [14-16] was used for all concrete elements. This model "is designed for applications in which concrete is subjected to monotonic, cyclic, and/or dynamic loading 


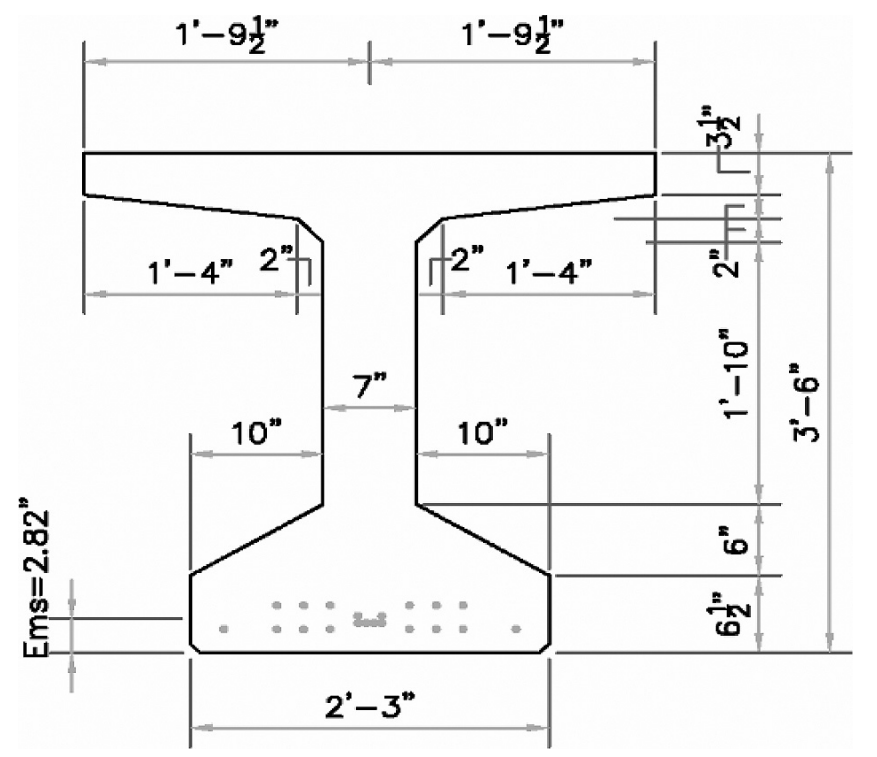

Fig. 1. Girder cross section at midspan.

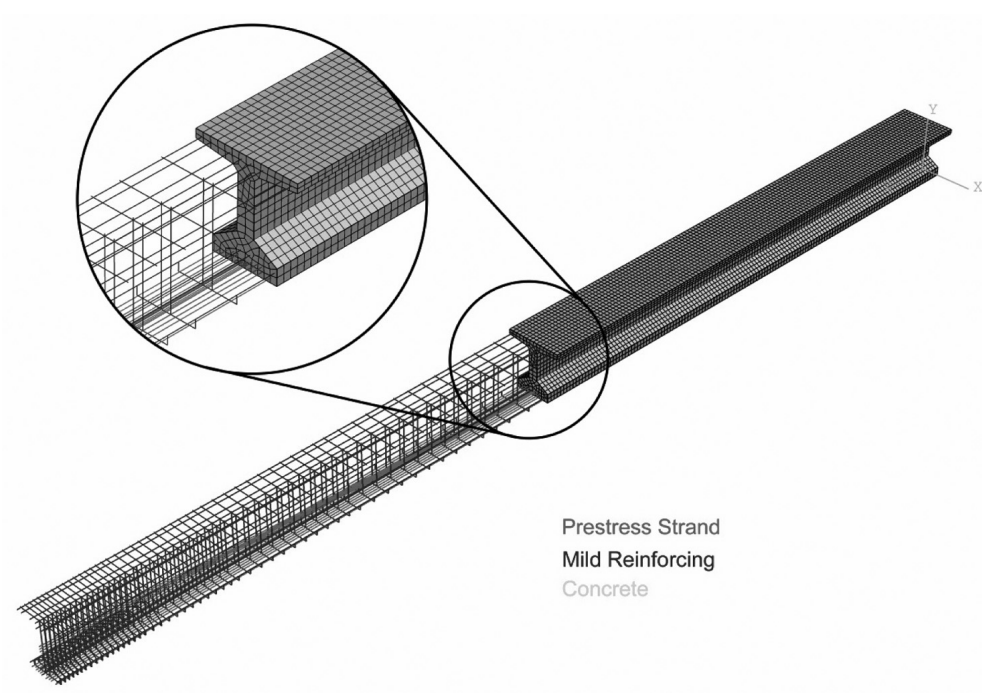

Fig. 2. Girder model.

under low confining pressures" [12]. Since the section is essentially completely unconfined, this material model is applicable. The plasticity model allows concrete's nonlinear properties to be described, while the damage model describes irreversible damage caused by crushing and cracking. The material properties are defined in terms of initial elastic properties, followed by stress/plastic strain data and information for tensile and compressive damage. Figure 3 shows the concrete properties used for the high-strength concrete of the girder. The dashed lines show the effect of the damaged modulus of elasticity.

The ends of the girder model were pin- and roller-supported effectively on a knife edge. This was simpler than modeling the actual bearing of the concrete on a polyurethane pad. As a result of this simplification, the material properties for elements in close proximity to the ends were forced to remain purely elastic to avoid unrealistic material failure from stress concentration at the idealized supports. This is acceptable since the area of interest is at midspan. 


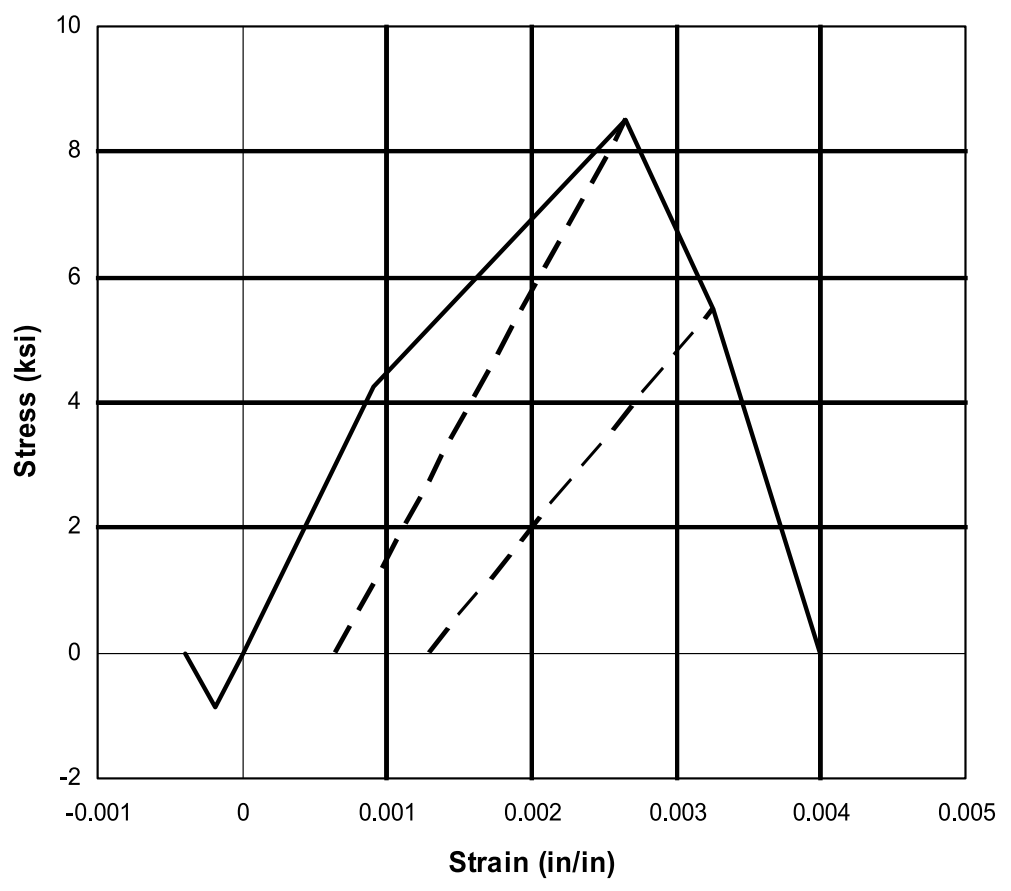

Fig. 3. High-strength concrete material properties.

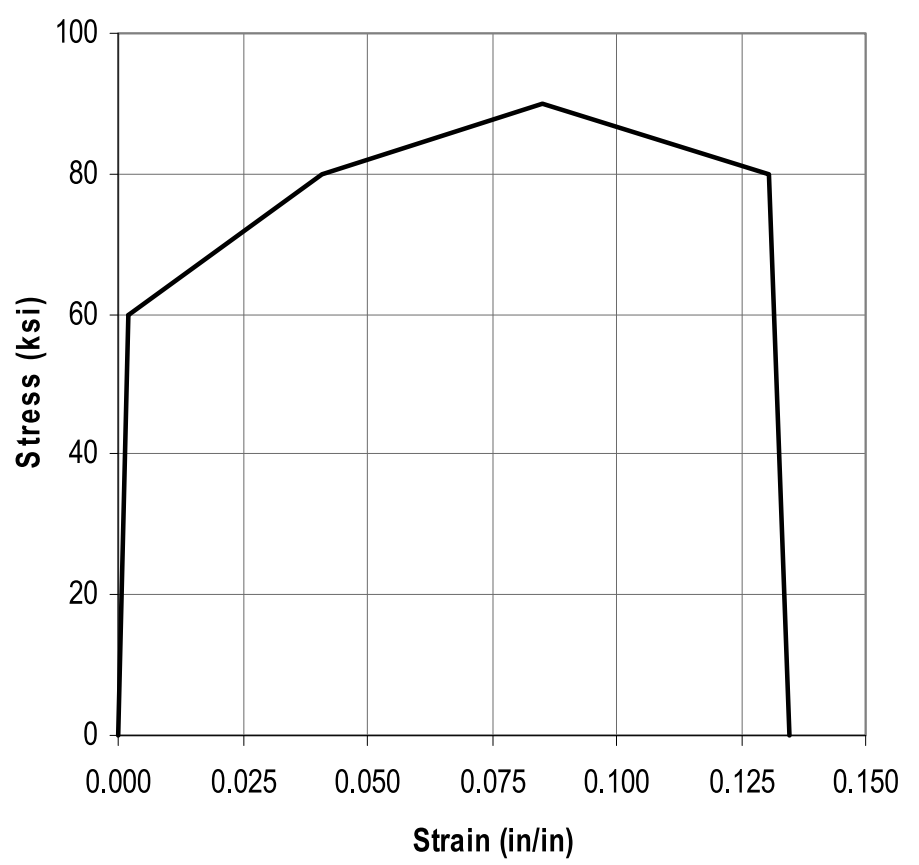

Fig. 4. Mild Reinforcing Steel Material Properties.

The prestressing and mild reinforcement were modeled with simple elastic-plastic models. A damage parameter was also introduced to account for breaking of the strands or bars. Figures 4 and 5 show the material properties used for the mild reinforcing and prestressing steel, respectively.

As much as possible, standard values for such items as stiffness, strength, plasticity, and damage were used. Time 


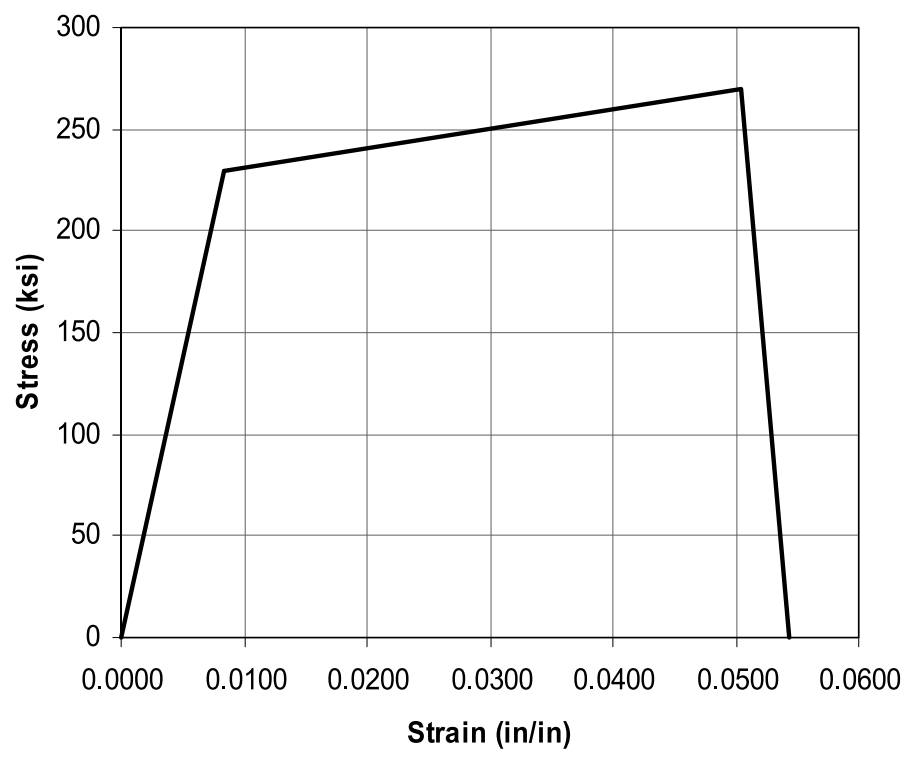

Fig. 5. Prestressing Steel Material Properties.

step size and variables that pertain to material softening were adjusted to obtain physically reasonable numerical results, as indicated by a realistic balance of energy. Material stress data could be specified as a function of strain rate, but that effect was not included because doing so resulted in severe numerical difficulties. As presented subsequently, the close agreement between the finite element results without strain rate effects and those of the experimental specimen confirms a similar conclusion by Stevens and Krauthammer [11] that a rate independent material model is adequate.

Before the dynamic blast load could be applied, the initial equilibrium state that includes prestressing and selfweight had to be found. Using the static analysis capabilities of ABAQUS/Standard, the prestressing force in the tendons was adjusted until the final specified value of 738 kips was obtained. The resulting static deflection at midspan was then examined. With prestressing, the initial upward deflection at midspan of the girder model was 0.958 inches, compared with a value prescribed by the manufacturer of 2.125 inches after 90 days. Taking creep into account, the results from the model were deemed to be acceptable.

Loading from the blast was applied as pressure on element surfaces. Within the ABAQUS software is the capability of considering a so-called "acoustic" load. Here, the properties of the fluid that surrounds the finite element model are given, and load is applied by specifying a pressure pulse at a source. A spherical pressure wave then proceeds over designated surfaces of the model. To determine the value and time of application of the initial pressure pulse, specialized software was used, entitled BEL (Bridge Explosive Loading), developed by the U. S. Army Corps of Engineers [17]. Among other things, BEL computes pressure-time histories for a given surface area, charge, and standoff.

Initially, the pressure pulse at the source was obtained from BEL and applied to the finite element model as an acoustic load. However, in comparison with data recorded at the actual test, the pressure values obtained from the spherical wave with actual fluid properties of air were shown to be quite inaccurate. The reason is likely that the high temperatures and the chemical reaction of the blast drastically modify the air properties. Because these effects are included in the formulation of BEL, a more accurate approach is to apply pressure results from BEL directly to the finite element model. Within ABAQUS is a feature that allows the user to input a peak pressure and then prescribe its spatial and temporal decay.

Two identical specimens were used for explosive tests. Under the direction of personnel from the Engineer Research and Development Center of the U. S. Army Corps of Engineers [13], two loading scenarios were executed: an explosion above the girder and an explosion below the girder. Explosive charges and standoff distances were selected based on preliminary analysis results. The goal was to damage the girders enough to cause total failure, but not to destroy them to the point that little would remain for observation. 


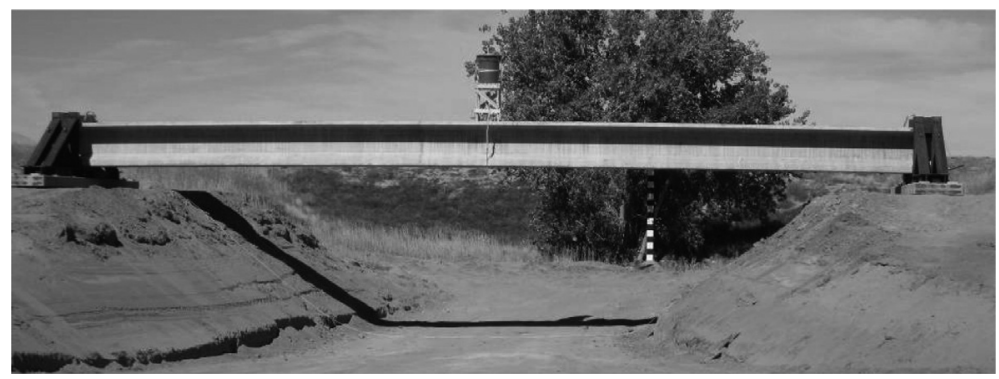

Fig. 6. Test setup (adopted from [13]).
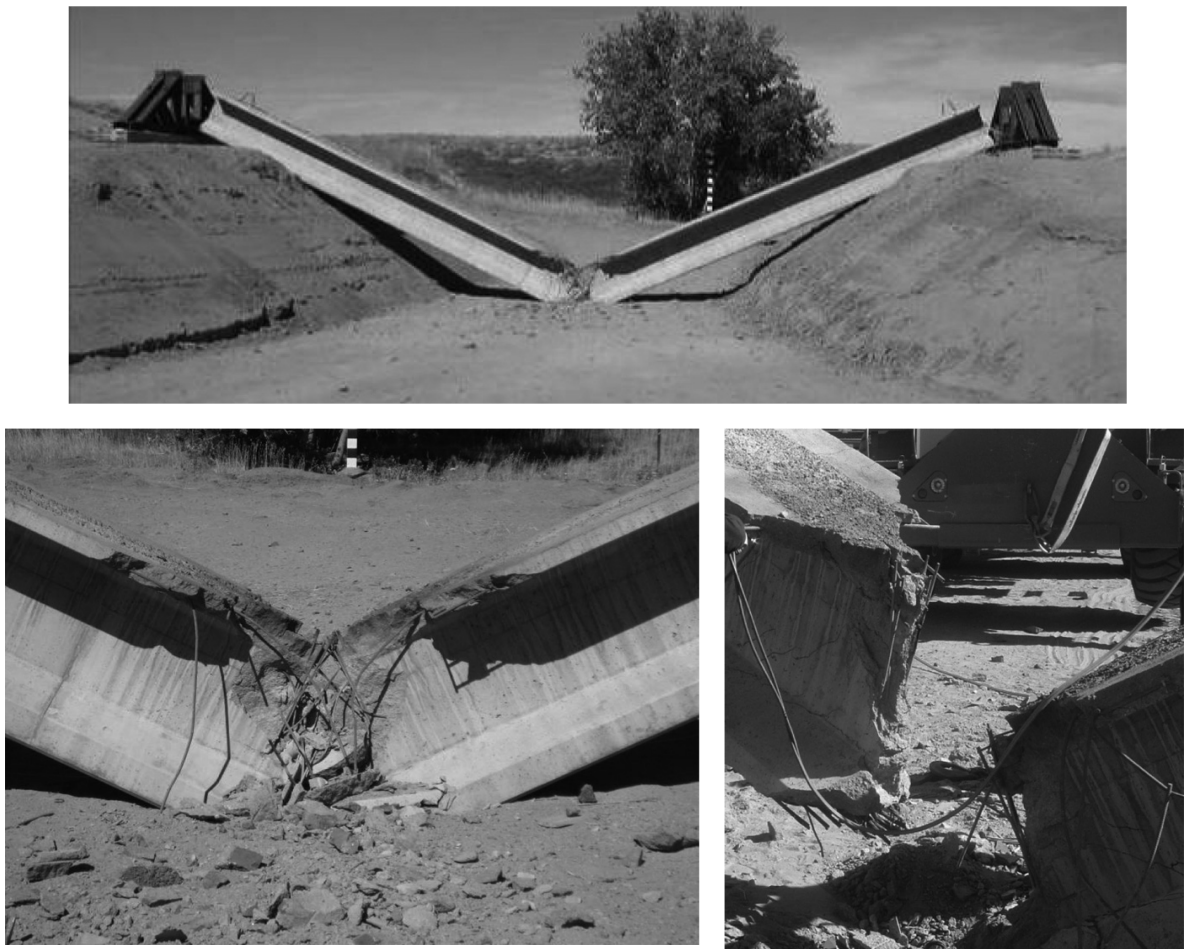

Fig. 7. Damaged girder from blast above midspan (adopted from [13]).

\section{Girder analysis for blast above}

For the scenario of loading from above, a spherical blast wave was assumed for pressure simulation. Figure 6 shows the test setup for the girder.

Examination of the girder after the test indicated that a little over 3.5 feet of the top flange and web had been blasted into small pieces. Additionally, heavy cracking could be seen for about four or five feet on either side of the destroyed web. Figure 7 shows the damaged girder. Note that, adjacent to the region of destruction at midspan, the edge of the remaining web is nearly vertical and that the top flange is sheared off at an angle for a short distance further. Also, while the bulb was damaged, the prestressing tendons were intact after the blast.

Near the location of the blast, large $45^{\circ}$ cracks were observed. There was also longitudinal cracking on the underside of the flange where it intersected with the web. This cracking pattern is consistent with shear failure at the location of the blast. Due to the high pressures and rapid application, the pressure wave essentially punched through the girder. The longitudinal cracking also indicates localized flexure of the flange. 


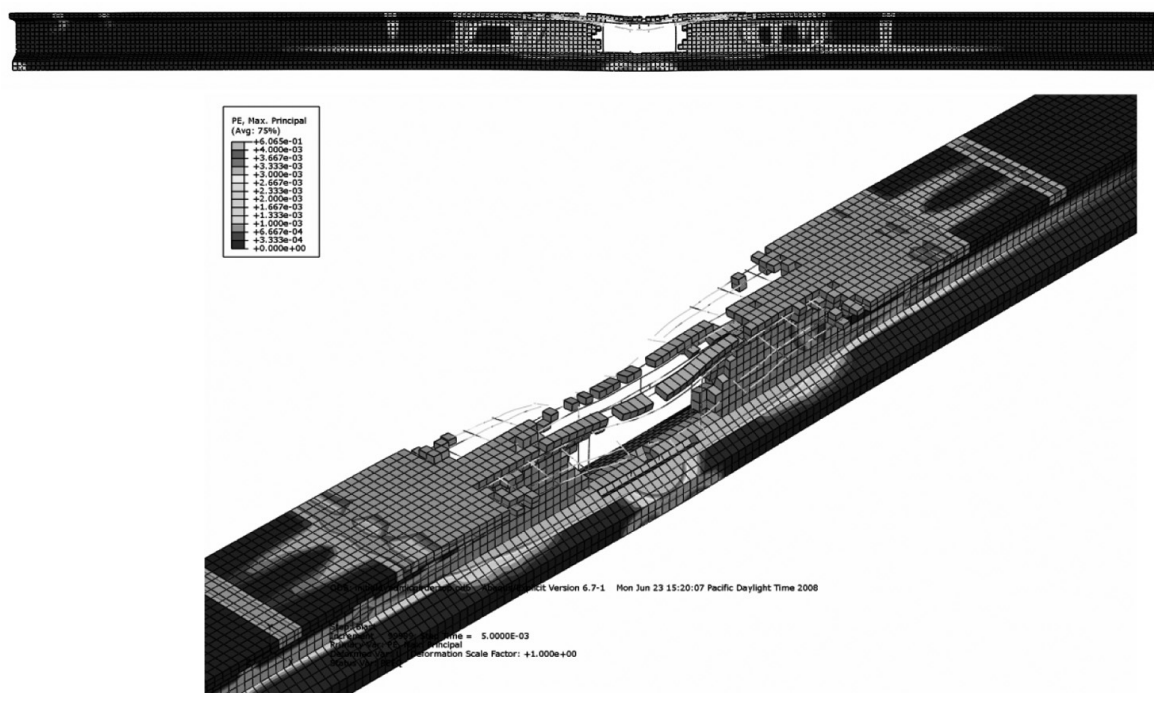

Fig. 8. Maximum principal plastic strain for the blast above the girder.

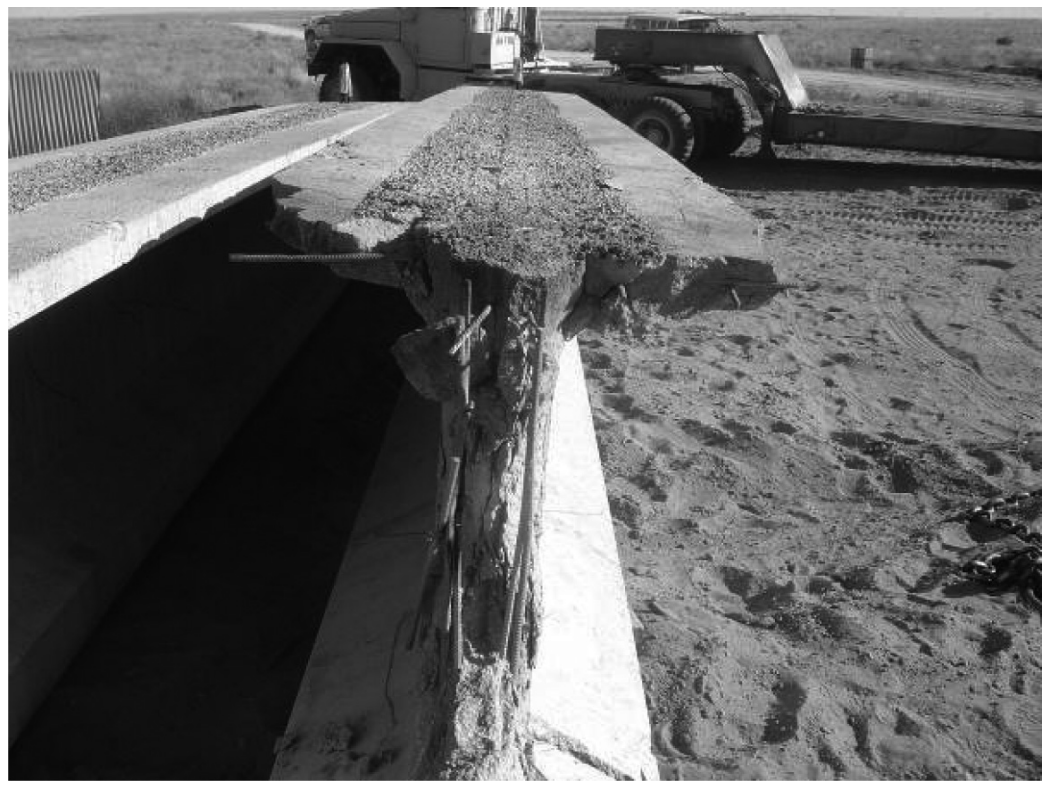

Fig. 9. Web cracking from blast above the girder.

The results for the finite element analysis of this blast are shown in Fig. 8. As previously mentioned, pressure values were obtained from the BEL software and applied directly to the top surface of the model. Small time steps of 5.0e- 08 seconds were used, and the total time period of the analysis was 5 milliseconds, which is approximately the length of time for the blast pressure wave to traverse the structure. To determine areas of significant cracking, the maximum principal plastic strain parameter was examined. Strains exceeding 0.004 are associated with heavy cracking. This limit is equivalent to ten times the tensile cracking strain and thus represents large, highly visible cracks. The model shows about ten feet of heavily cracked concrete. Localized bending of the flange is also observed in the model.

Figure 8 shows the model at the end of the pressure wave application ( 5 milliseconds). All material shown in gray indicates heavily cracked concrete (maximum principal plastic strain greater than 0.004 ). The removed elements 


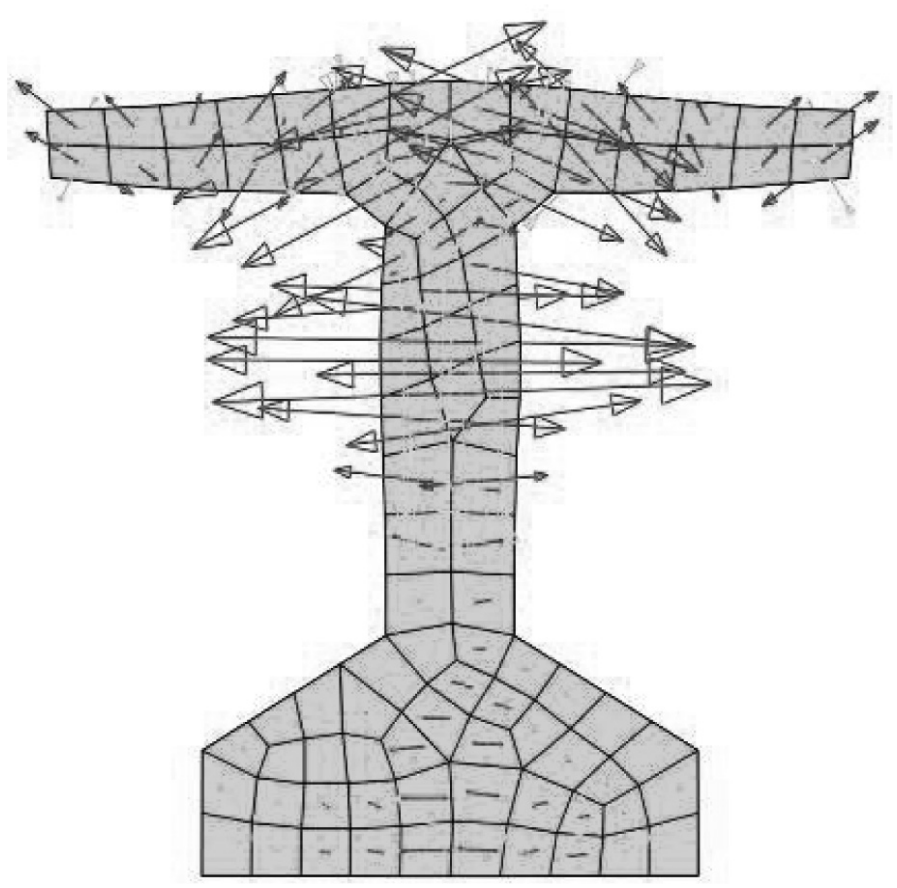

Fig. 10. Web plastic strain from blast above the girder.

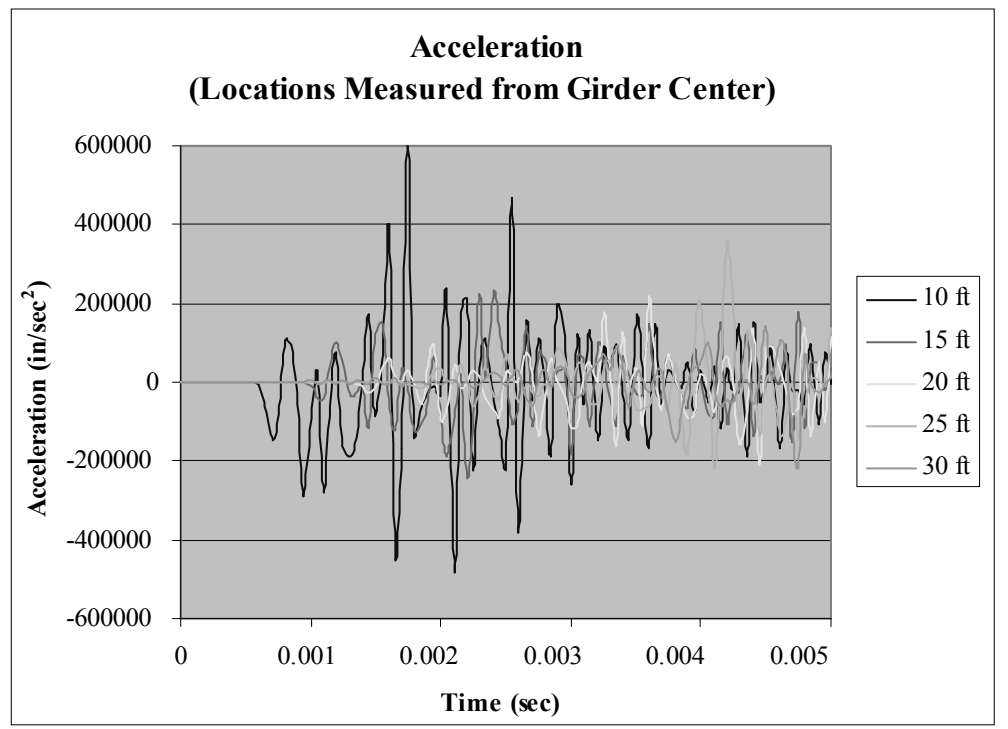

Fig. 11. Acceleration time history for blast above the girder.

are associated with rubbelized concrete (equivalent plastic strain greater than 0.02). This limit was derived from observations of the actual blast tests.

Examination of the damaged cross section reveals vertical cracks within the web, as shown in Fig. 9. A plot of the direction of principal plastic strain within the model reveals the same type of cracking, as shown in Fig. 10. Clearly, the nature and extent of damage are well predicted by the finite element model.

To check the validity of the pressure loads applied, the results from pressure sensors placed on the top of the flange 


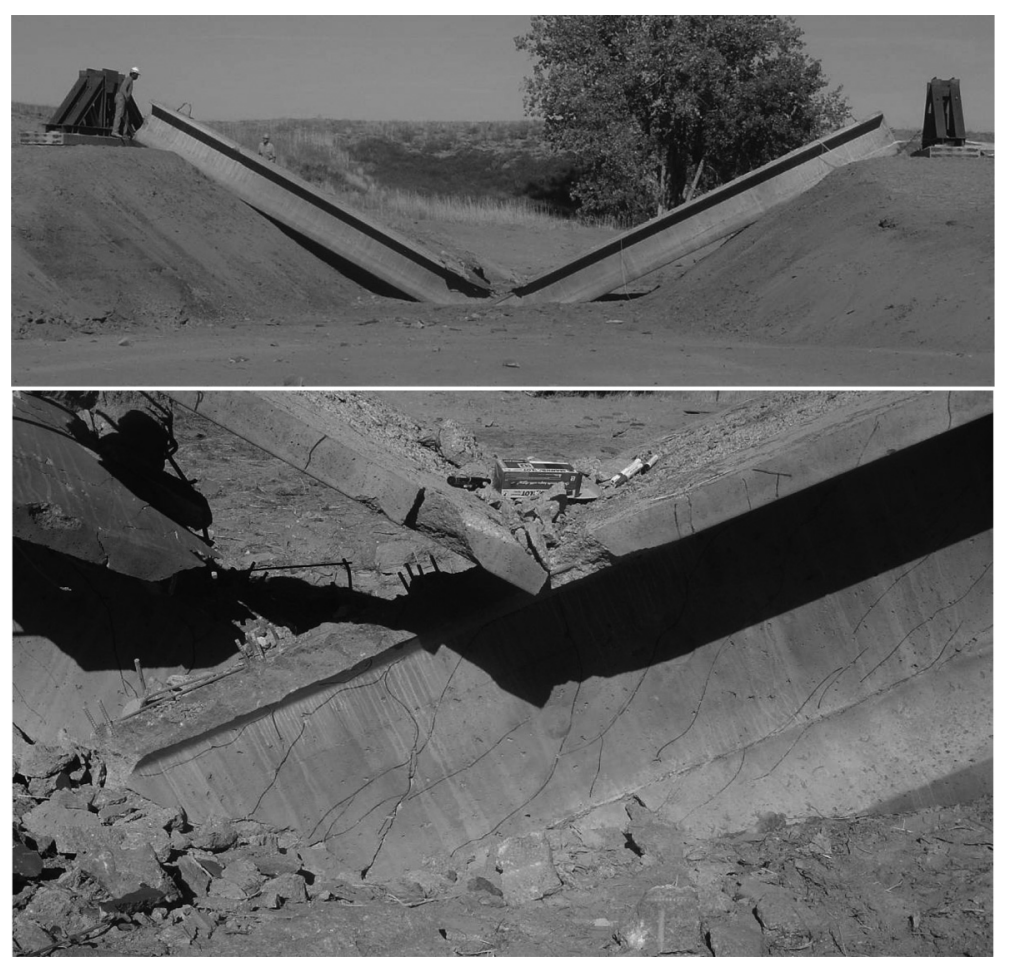

Fig. 12. Damage from the blast below the girder.

were compared with pressures predicted by BEL. Close agreement was observed.

Accelerometers were also placed on the test specimen. A peak acceleration of approximately $6.5 \mathrm{e} 5 \mathrm{in} . / \mathrm{sec}^{2} \mathrm{was}$ measured at ten feet from midspan. Within the finite element model, a peak acceleration of approximately $6.0 \mathrm{e} 5$ in./ $\mathrm{sec}^{2}$ was seen at the same location, as shown in Fig. 11. These are very consistent results.

\section{Girder analysis for blast below}

For the scenario of blast loading below the girder, the test setup was similar to that of the blast from above except that additional plates were welded to the supports to hold the girder down [13].

Pressure sensors located on the girder once again measured the blast wave. This time however, there was a notable difference between predicted pressures and measured values. It was seen that the pressures obtained from BEL may be two to three times the actual value [13]. Thus, it is expected that the damage and cracking in the finite element model should be greater than that observed. It is noted here that BEL is intended for predicting pressures on the top of flat bridge decks. In that case, it does not include the ability to account for wave reflection off the ground. In addition, it cannot account for the complicated geometry below the bridge deck. Thus, it is not well suited to predicting pressures on anything other than a flat surface. However, it is the best tool currently available for this research.

The damaged girder after the blast from below is shown in Fig. 12. Examination of the girder after the test indicated that less than a foot of the web had been rubbelized, although a length of about nine feet was missing from the top flange. It is noted that the detached top flange may have been a result of the girder falling rather than an exclusive result of the blast wave. Additionally, heavy cracking could be seen for about ten feet on either side of the destroyed web.

Near the location of the blast, large $45^{\circ}$ cracks were again observed. These were oriented in the opposite direction of the blast from above scenario, as would be expected. This cracking pattern is consistent with shear failure at the 


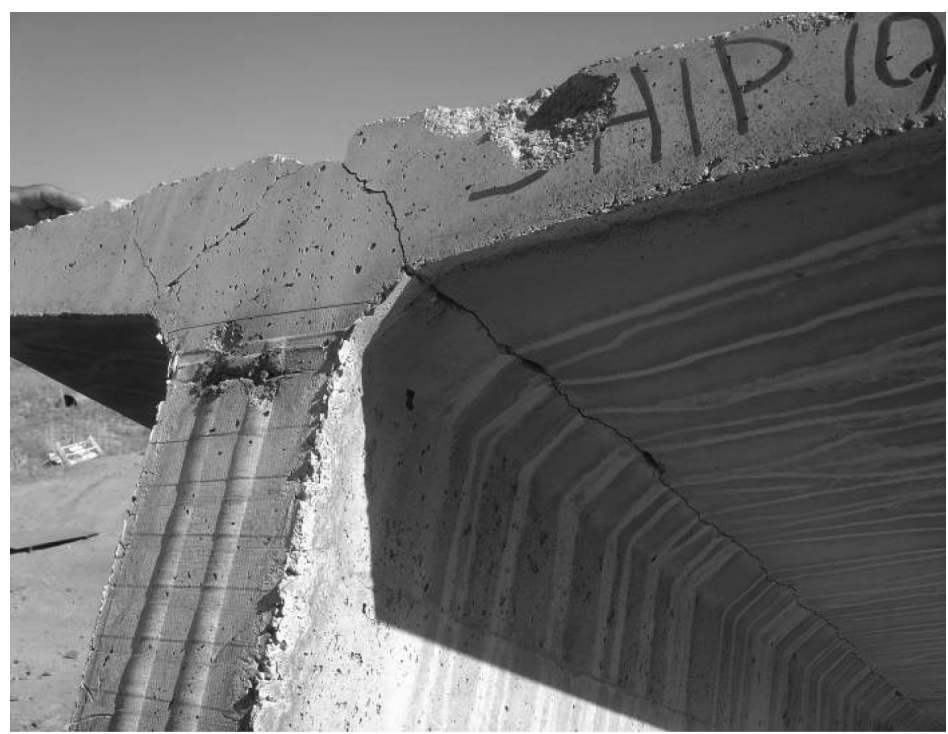

Fig. 13. Longitudinal cracking at web-flange intersection.

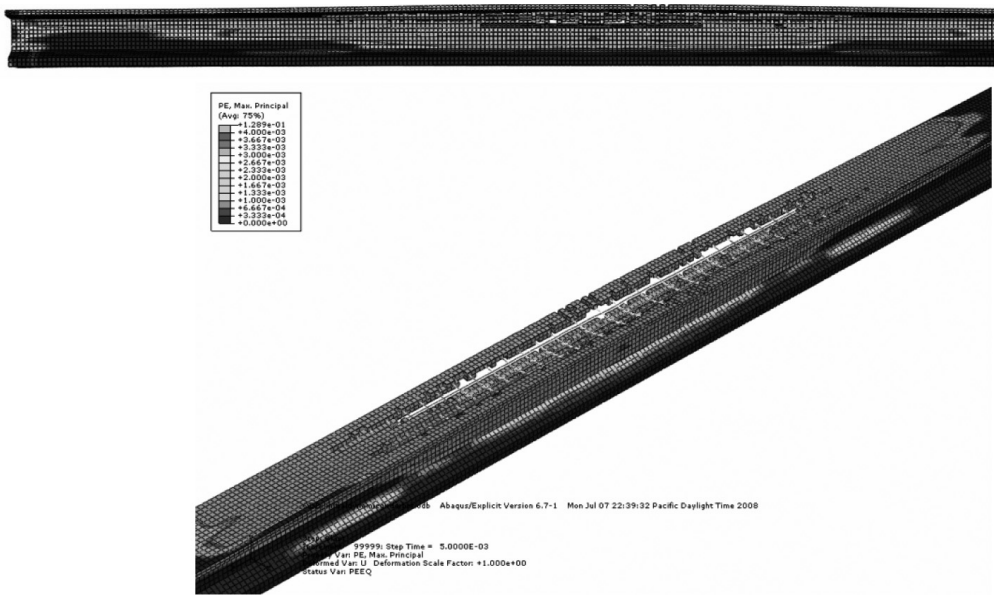

Fig. 14. Maximum principal plastic strain for blast below the girder.

location of the blast, similar to the first scenario. Longitudinal cracking was also observed in this case, but to a much larger degree than before. Figure 13 shows this cracking pattern.

These observations are consistent with the results from the finite element model, in which heavy cracking is indicated through the middle third of the girder. Figure 14 shows maximum principal plastic strain. Once again the gray is associated with heavy cracking while removed elements were subject to very large plastic strain, indicating rubbelized concrete.

The damage indicated in the model compares reasonably well to observed results, considering the difference between actual and predicted pressure. It is noted, however, that in addition to the difference in pressure, ABAQUS/Explicit is not able to account for shadowing effects and wave reflection without modeling the fluid surrounding the girder. The pattern and amount of damage is still informative, however. It can be seen that the cracking at the web-flange intersection is shown all along the length of the girder, as was observed in the test specimen (Fig. 13). The model shows rubbelized concrete and detachment of the upper flange for a significant length of the girder, which agrees with the damage observed in half of the specimen shown in Fig. 15. Extensive damage was not predicted for the bulb, but some of the damage observed could have occurred from deformation after the blast 


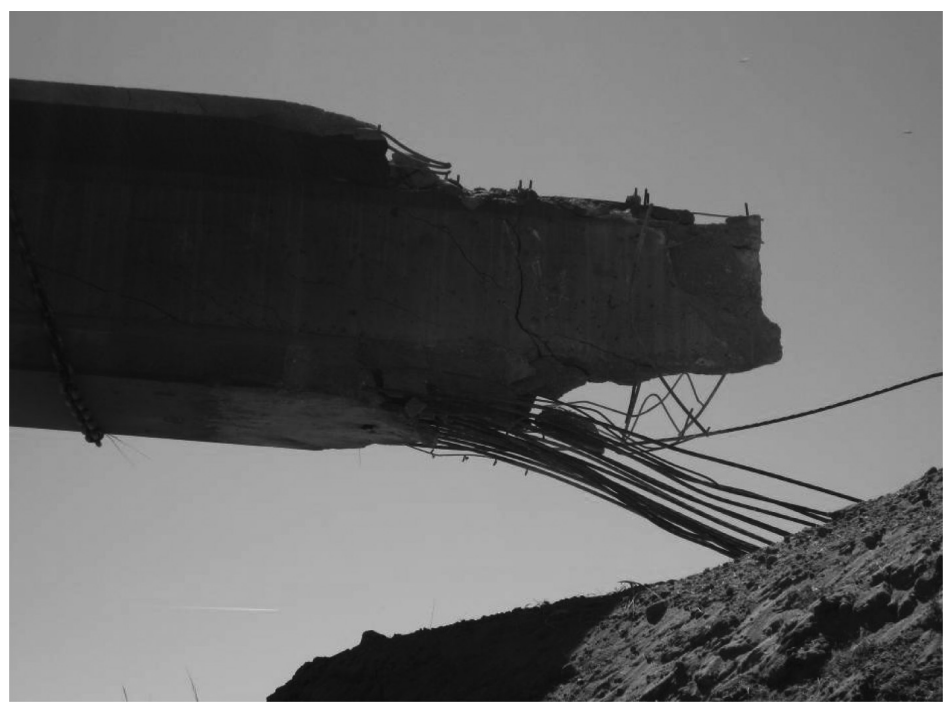

Fig. 15. Damaged section with rubbelized concrete removed (adopted from [12]).

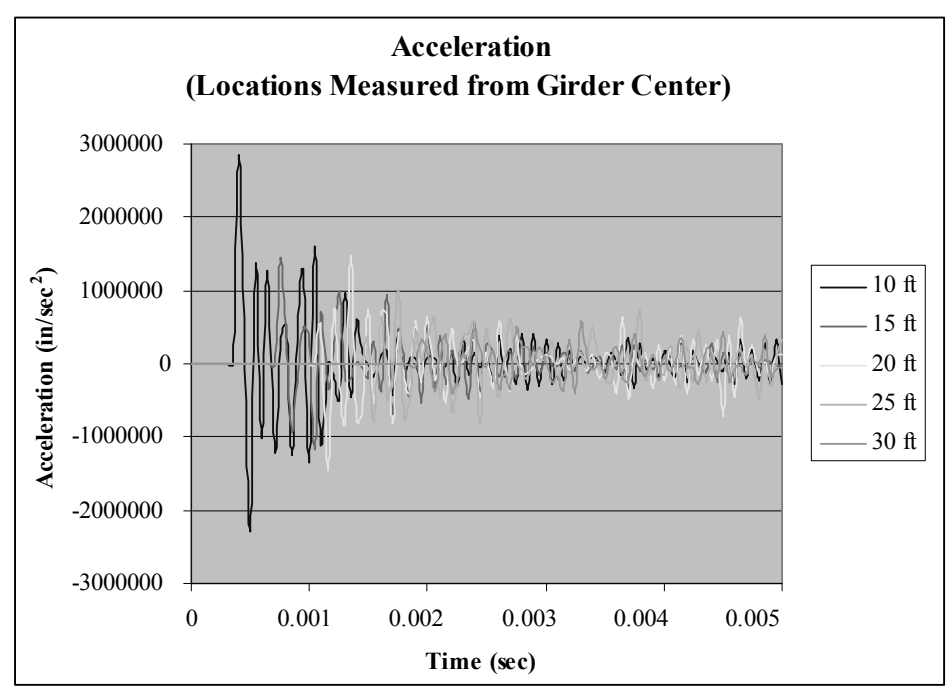

Fig. 16. Acceleration for blast below the girder.

and impact with the ground. However, the results are acceptable considering the simplified pressures applied to the model. Approximately 25 feet of cracking in the web can be seen in the model, similar to the 20 feet observed in the full-scale test.

Accelerometers were also placed on this specimen. Maximum acceleration of the girder at ten feet from midspan was measured as approximately $7.5 \mathrm{e} 6 \mathrm{in} . / \mathrm{sec}^{2}$. The finite element model shows a peak acceleration of $3.0 \mathrm{e} 6 \mathrm{in} . / \mathrm{sec}^{2}$ at the same location, shown in Fig. 16. These values are not as consistent as the previous case, but they are of the same order of magnitude and thus reasonable. Overall, the model is acceptable.

\section{Finite element model of a bridge deck}

Using the girder model described above, a complete bridge deck model was developed as shown in Fig. 17. Utilizing symmetry, only half of the span was included in the model, thus limiting loading scenarios to blast events 


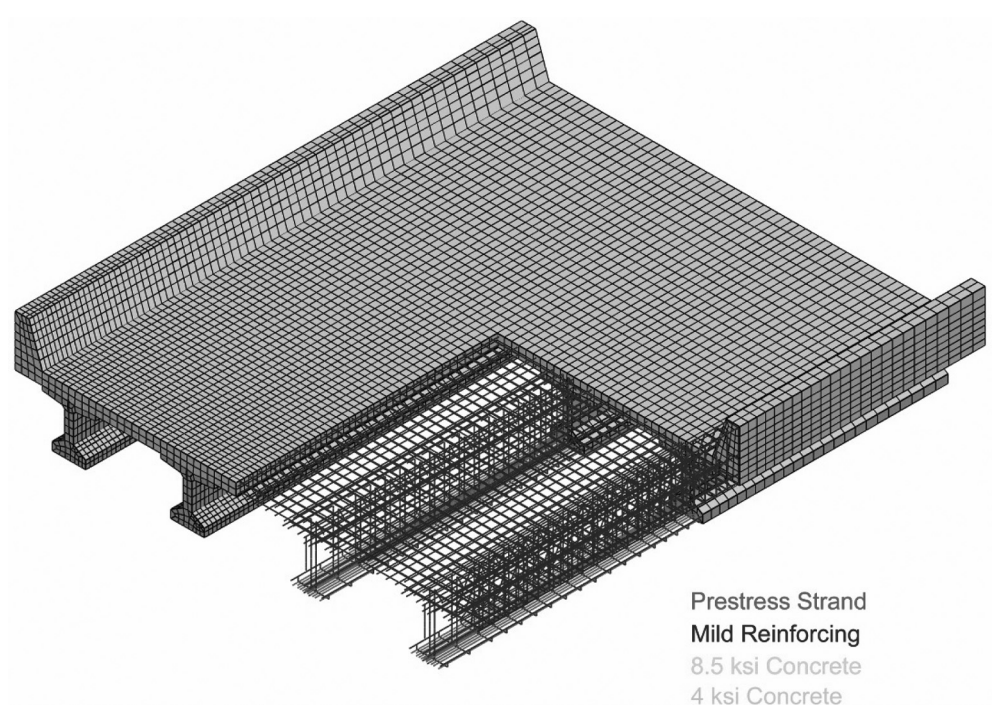

Fig. 17. Finite element model for the bridge deck.

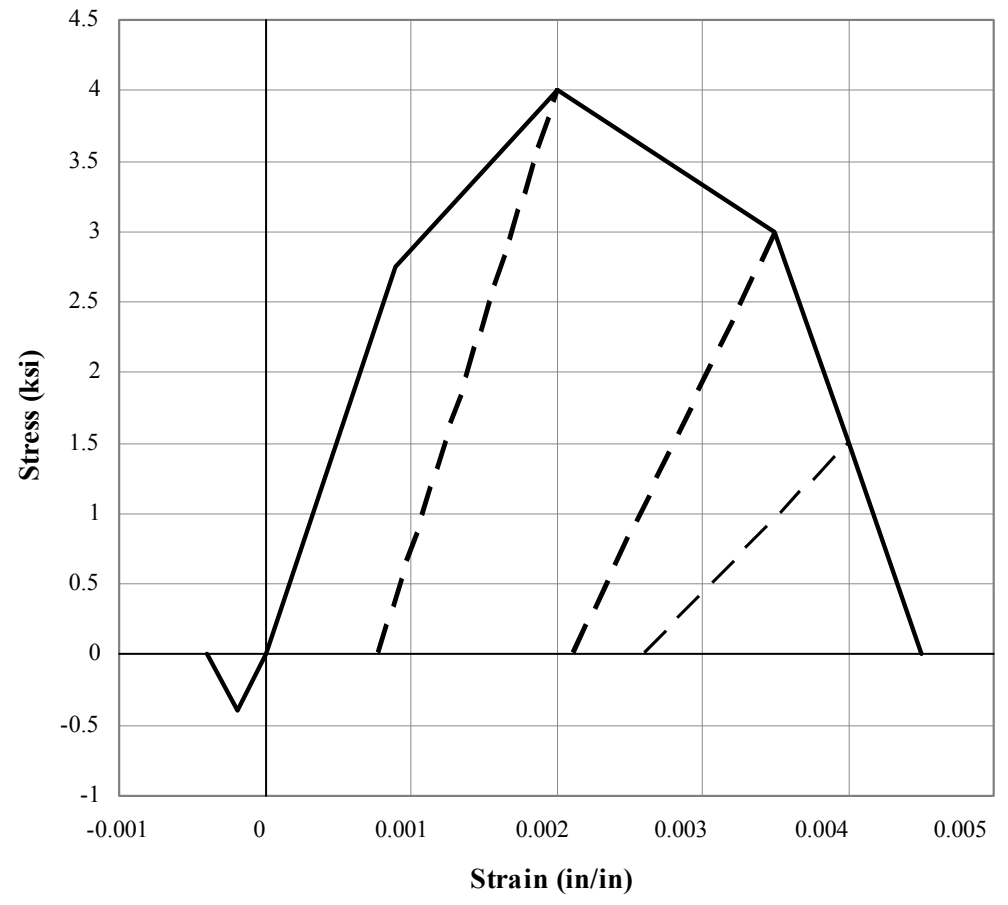

Fig. 18. Slab concrete material properties.

at the midspan of the bridge. This was necessary, however, due to the high computer memory demand.

No changes were necessary in the materials, although a lower strength concrete material was created for the deck. This material model is shown in Fig. 18. Along the mirrored surface at midspan, all nodes were fixed out of plane. The outer end of the bridge model remained roller-supported on a theoretical knife edge, as with the girder model.

Computer memory issues prevented the slab from being free of the prestressing, as would typically be the case in practice. The girder and bridge are both modeled as a mass of concrete and embedded prestressing strands with a given force. Thus, the bridge model effectively has some prestressing in the slab. Acknowledging this effect, it is 


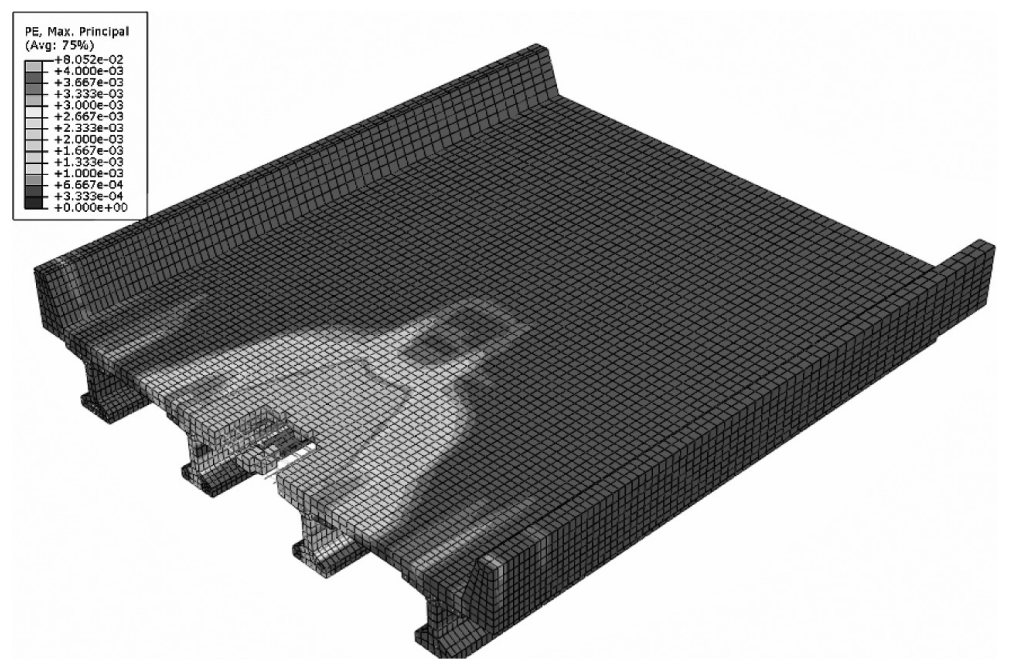

Fig. 19. Maximum principal plastic strain, blast above, between girders. Top view.

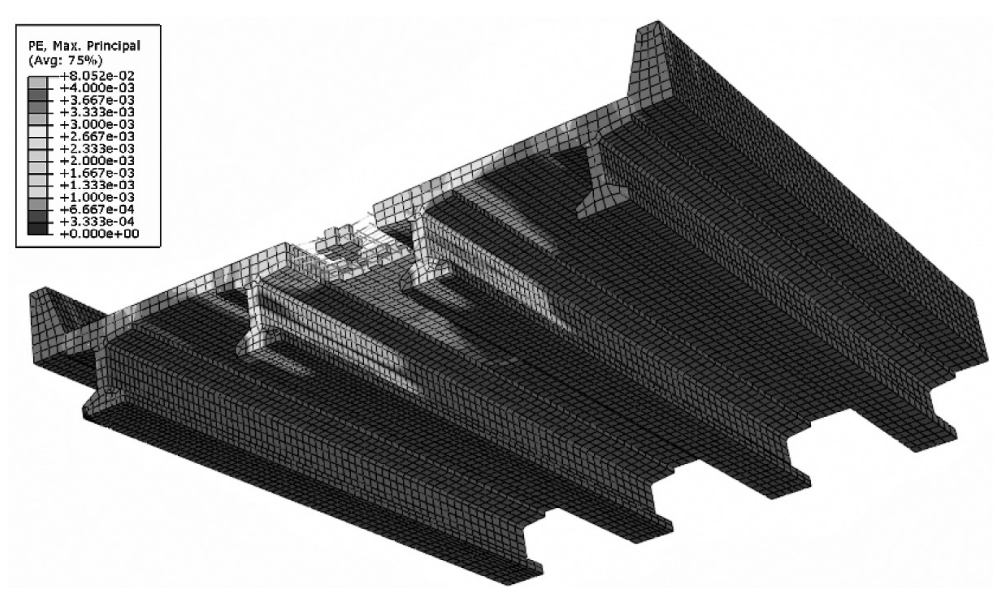

Fig. 20. Maximum principal plastic strain, blast above, between girders. Bottom view.

believed that the results derived from the model are reasonable.

As with the girder analysis, the analysis time was set at 5 milliseconds with a prescribed step of 50 nanoseconds. The 5 millisecond run time was the time it took for the blast wave to move across the bridge.

Three different blast event scenarios were investigated using finite element analysis. The technique for applying pressure loading on the girder model was also used for the bridge investigation. Thus, using BEL, a pressure wave was applied at midspan directly above the centerline between the two interior girders and at midspan directly above an interior girder. Then, a pressure wave was applied at midspan directly below the centerline between the two interior girders.

\section{Bridge analysis with blast above the deck, between girders}

Plots of the maximum principal plastic strain for the blast above the bridge and between the interior girders are shown in Figs 19, 20, and 21. Using the same criteria to detect cracking and rubbelized concrete that was used for the girder models, the plot shows that the blast punches a hole in the deck slab. Heavy cracking was also observed surrounding the hole in the region between the girders. The interior girders show a small area of cracking along the 


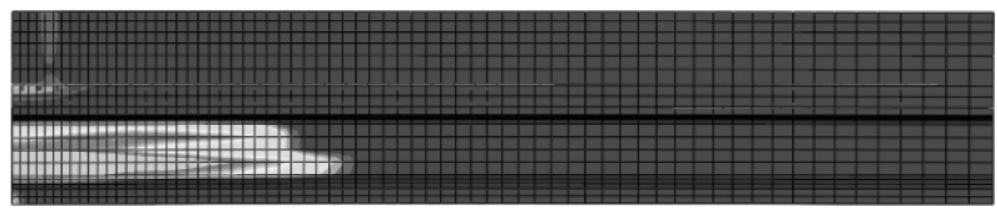

Fig. 21. Maximum principal plastic strain, blast above, between girders. Side view of interior girder.

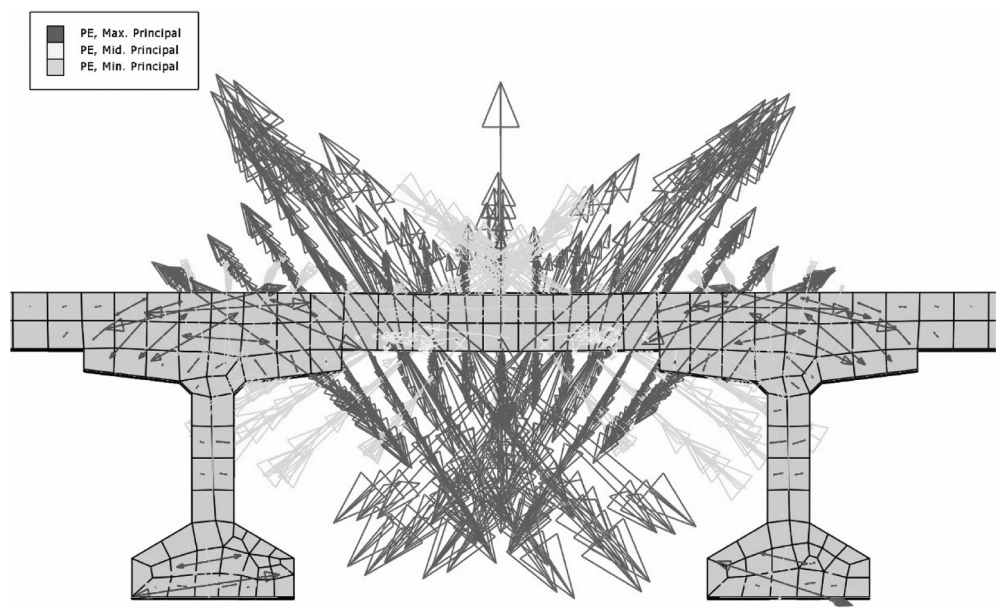

Fig. 22. Principal plastic strain direction, blast above, between girders.

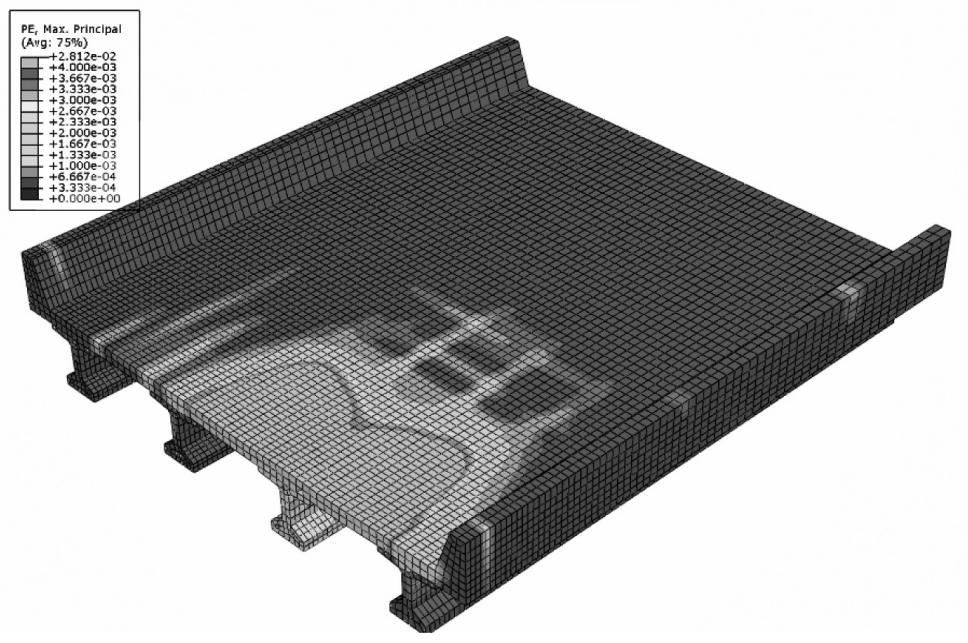

Fig. 23. Maximum principal plastic strain, blast above, centered on a girder. Top view.

girder web near the bulb. The exterior girders and traffic barriers show no significant damage. Therefore, the girders should not see any significant reduction in strength, even the ones adjacent to the blast.

Examining the direction of principal plastic strain illustrates again that shear is the predominant form of failure in the deck. At less than one millisecond into the analysis, when the pressure wave is still being applied, the strong tendency to punch through the deck can be seen. This is shown in Fig. 22.

These results imply that at this level of blast, the bridge would not be destroyed. If the bridge was wide enough, the area with the damaged slab could even be blocked off and the rest of the lanes of traffic could be immediately reopened. 


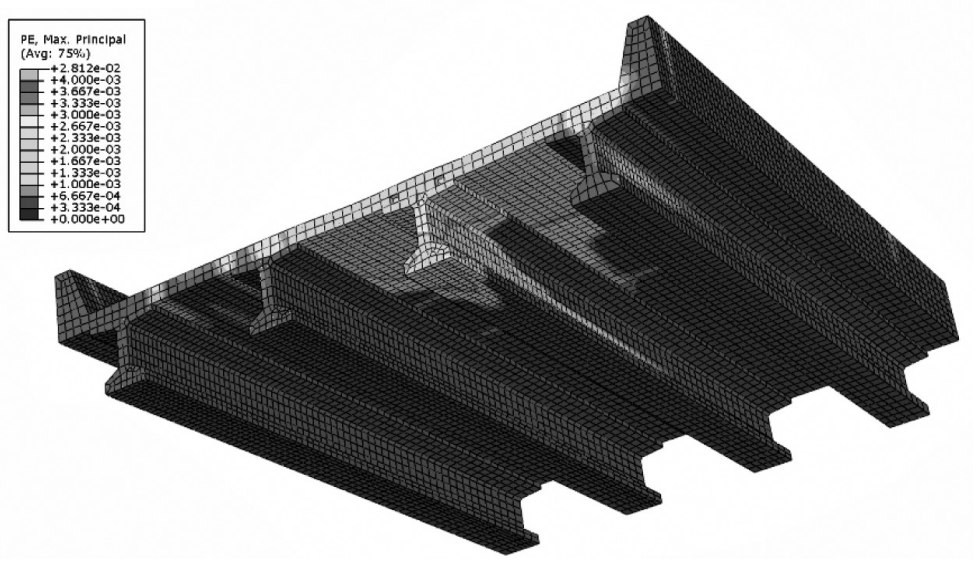

Fig. 24. Maximum principal plastic strain, blast above, centered on a girder. Bottom view.

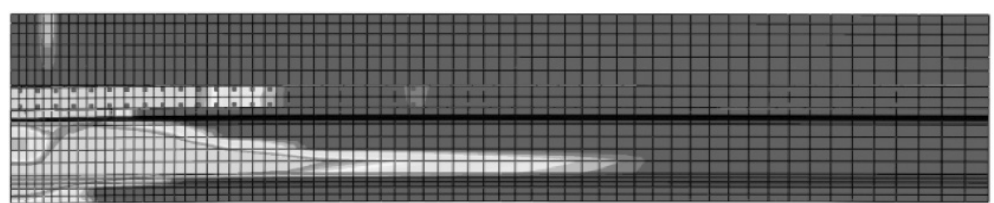

Fig. 25. Maximum principal plastic strain, blast above, centered on a girder. Side view of internal girder.

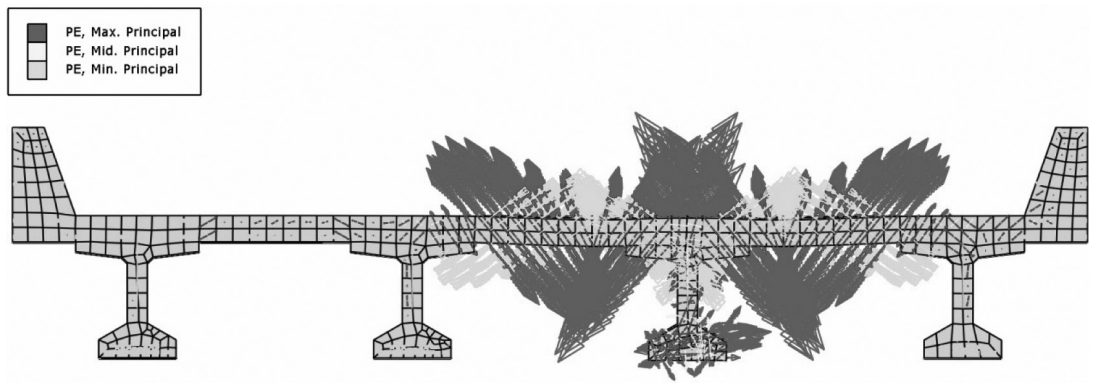

Fig. 26. Principal plastic strain direction, blast above, centered on a girder.

\section{Bridge analysis with blast above the deck, centered on a girder}

Plots of the maximum principal plastic strain for the blast above the bridge and centered on an interior girder are shown in Figs 23, 24, and 25. For this case, it is observed that very little if any concrete is rubbelized, although there is significant cracking. It would appear that having the girder immediately under the center of the blast is enough to stiffen the slab to the point that a punching failure does not occur. Additionally, the slab provides enough protection to the girder to prevent total demolition.

The extent of cracking for this loading scenario is similar to the case above the deck and between the girders. In the transverse direction, heavy cracking extends to the adjacent girders on either side of the blast event. The girder immediately below the blast source shows heavy cracking all the way through its depth. The adjacent girders, however, show no significant cracking.

Examination of the direction of cracking at the end of the analysis shows a slight difference in the failure pattern. Instead of seeing a single cone-shaped failure surface where the blast load punches through the deck, it is observed that there is a cone-shaped failure surface on either side of the girder. This trend is illustrated in Fig. 26. This is just further confirmation that the girders offer stiffening and protection to the slab. 


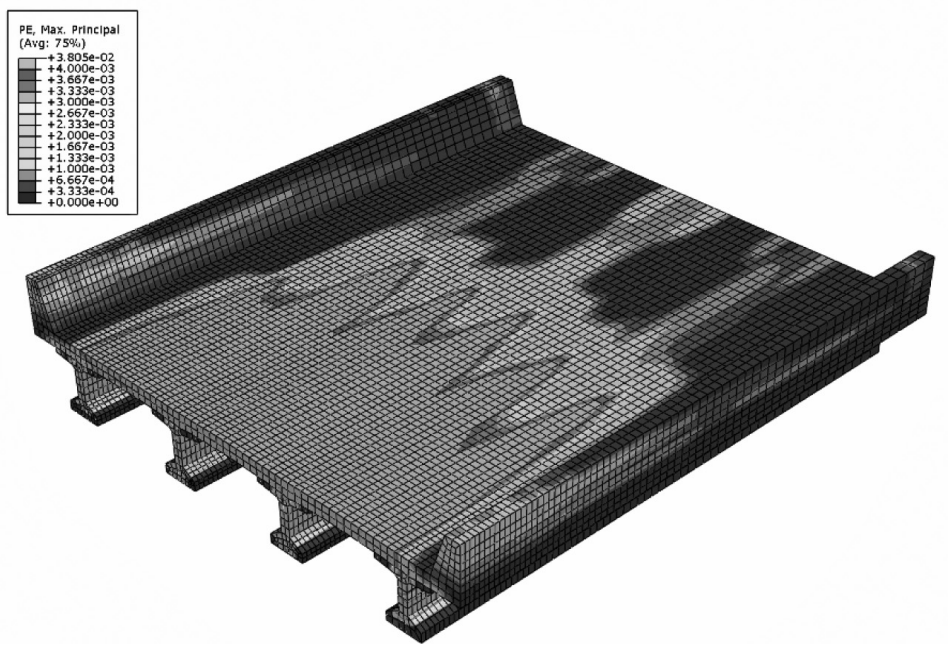

Fig. 27. Maximum principal plastic strain, blast below. Top view.

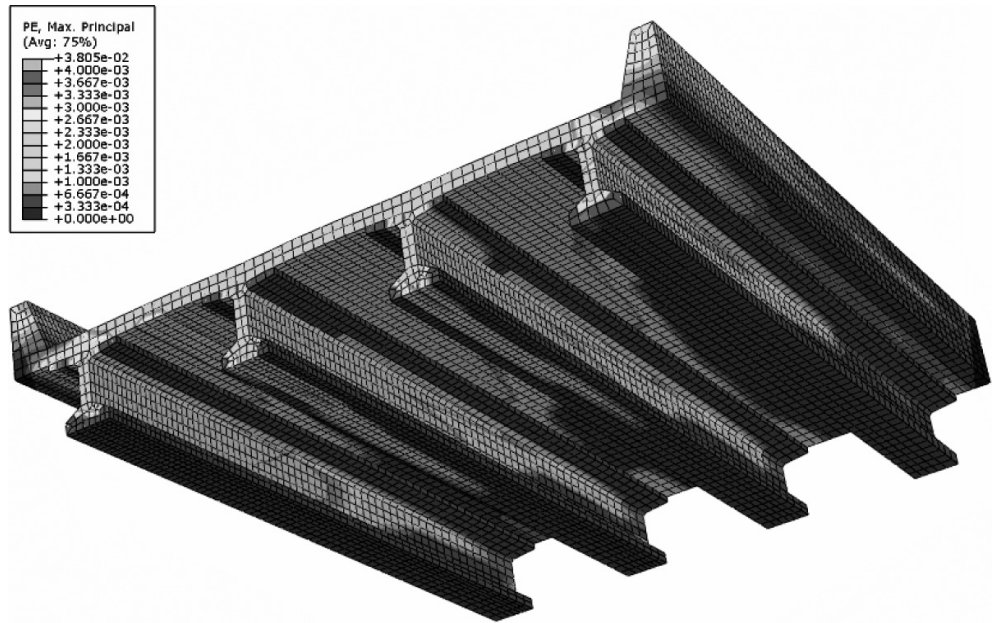

Fig. 28. Maximum principal plastic strain, blast below. Bottom view.

For both explosive events above the deck, it is seen that, except for the area immediately below the blast source, the presence of a girder is effective for stiffening the slab and stopping the propagation of heavy cracking. Once again, it can be concluded that for a wide enough bridge, some lanes may be reopened immediately after the event. Even if a single lane can remain open, this would allow emergency vehicles to be uninterrupted in their service.

\section{Bridge analysis with blast below the deck}

Plots of the maximum principal plastic strain for the blast below the bridge are shown in Figs 27, 28, and 29. It is once again seen that very little if any concrete is rubbelized. However, the extent of cracking is much greater than for either of the blast scenarios from above. All four girders show heavy cracking through the full depths of their webs. The deck also shows cracking along its full width, and extending longitudinally for about half the total bridge span.

It must be noted that for this load case below the bridge, wave reflection can have significant effects. As the wave reflects off the sides of the girders, they may see increased pressures as multiple reflected waves intersect and merge. 


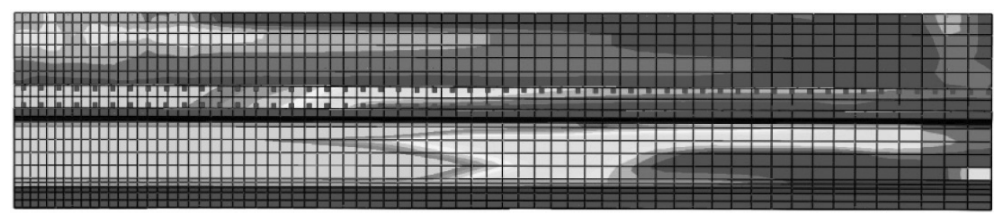

Fig. 29. Maximum principal plastic strain, blast below. Side view of interior girder.

There is also the effect of wave reflection off the ground to consider. However, it is known from the experiments that the incident wave pressure applied to the girder was less than that used in the model, so it is speculated that pressure is overestimated here, and thus the results are expected to be conservative.

\section{Summary and conclusions}

A finite element model of a precast, prestressed concrete girder was created and subjected to blast loading above and below. The results were compared to full-scale experiments and close agreement of type and extent of damage was observed. The primary mode of failure for both scenarios was localized concrete rubbelization and shear failure, leading to overall structural instability and collapse. Applied blast pressures based on acoustic loading and typical fluid properties of air were shown to be inaccurate, but pressures from the specialized software, BEL, matched experimentally measured values well, especially for the blast above the girder.

A four-girder, simple-span bridge deck model was developed and analyzed for two blast scenarios above the deck and one below. For the blast load applied above the deck, between two girders, the pressure punched a hole through the slab, but left the girders relatively untouched. When the blast was centered over an interior girder, the pressure caused damage to the girder directly below the blast source and to the surrounding slab. In both cases, the bridge is expected to remain standing and sections of it are expected to be immediately serviceable.

For the blast load applied below the deck, heavy cracking was seen through the middle half of the bridge, especially in the slab, but also in the webs of the girders. Thus, while the bridge will remain standing, it is likely that it will not be immediately serviceable. However, it should be noted that the pressure loading for this case did not include reflection from the ground and structural members. Detailed analysis that includes a mesh of the air is suggested to account for shadowing effects and wave reflection.

\section{Acknowledgements}

This research was conducted through the Washington State Transportation Research Center (TRAC) with funding from the Federal Highway Administration (FHWA) under contract DTFH61-05-C-00008. The technical contributions by Hamid Ghasemi of the FHWA, Ron Lewis of the Washington State Department of Transportation (WSDOT) Bridge Office, and James Ray of the USAE Engineer Research and Development Center are gratefully acknowledged.

\section{References}

[1] Washington State Department of Transportation (2010), http://www.wsdot.wa.gov/Bridge/Reporting/BridgesByNumbers.htm.

[2] K. Marchand, E.B. Williamson and D.G. Winget, Analysis of Blast Loads on Bridge Substructures, in: Structures Under Shock and Impact VIII, N. Jones and C.A. Brebbia, eds, Computational Mechanics Inc., Billerica, Ma, 2004, pp. 151-160.

[3] D.G. Winget, K.A. Marchand and E.B. Williamson, Analysis and Design of Critical Bridges Subjected to Blast Loads, Journal of Structural Engineering 131(8) (2005), 1243-1255.

[4] E.B. Williamson and D.G. Winget, Risk Management and Design of Critical Bridges for Terrorist Attacks, Journal of Bridge Engineering 10(1) (2005), 96-106.

[5] N. Ishikawa, H. Enrin, S. Katsuki and T. Ohta, Dynamic Behavior of Prestressed Concrete Beams Under Rapid Speed Loading, in: Structures Under Shock and Impact V, N. Jones, D.G. Talaslidis, C.A. Brebbia and G.D. Manolis, eds, Computational Mechanics Inc., Billerica, Ma, 1998, pp. 717-726. 
[6] N. Ishikawa, S. Katsuki and K. Takemoto, Dynamic Analysis of Prestressed Concrete Beams Under Impact and High Speed Loadings, in: Structures Under Shock and Impact VI, N. Jones and C.A. Brebbia, eds, Computational Mechanics Inc., Billerica, Ma, 2000, pp. $247-256$.

[7] N. Ishikawa, S. Katsuki and K. Takemoto, Incremental Impact Test and Simulation of Prestressed Concrete Beam, in: Structures Under Shock and Impact VII, N. Jones, C.A. Brebbia and A.M. Rajendran, eds, Computational Mechanics Inc., Billerica, Ma, 2002, pp. $489-498$.

[8] J. Magnusson and M. Hallgren, Reinforced High Strength Concrete Beams Subjected to Air Blast Loading, in: Structures Under Shock and Impact VIII, N. Jones and C.A. Brebbia, eds, Computational Mechanics Inc., Billerica, Ma, 2004, pp. 53-62.

[9] R.M.M. Van Wees and J. Weerheijm, Simulation of Concrete Beams Under Explosive Loading with the Finite Element Method, Structures Under Shock and Impact, P.S. Bulson, ed., Elsevier Science Publishing Company Inc., New York, N.Y, 1989, pp. 97-106.

[10] Q. Fang, Q.-H. Qian and Y.-L. Shi, A Rate-Sensitive Analysis of R/C Beams Subjected to Blast Loads, in: Structures Under Shock and Impact IV, N. Jones, C.A. Brebbia and A.J. Watson, eds, Computational Mechanics Inc., Billerica, Ma, 1996, pp. 221-230.

[11] D.J. Stevens and T. Krauthammer, Nonlinear Finite Element Analysis of Impulse Loaded RC Beams, in: Structures Under Shock and Impact, P.S. Bulson, ed., Elsevier Science Publishing Company Inc., New York, N.Y, 1989, pp. 41-53.

[12] ABAQUS Software and Documentation, Version 6.5. (C) Dassault Systèmes, SIMULIA, Providence, RI.

[13] C. Ertle, J. Ray, B. Walker and S. Johnson, Explosive Tests of Precast, Prestressed Bridge Girders, Data Report No. WA-RD 718.1, Washington State Department of Transportation, Olympia, WA, 2008.

[14] A. Hillerborg, M. Modeer and P.E. Petersson, Analysis of Crack Formation and Crack Growth in Concrete by Means of Fracture Mechanics and Finite Elements, Cement and Concrete Research 6 (1976), 773-782.

[15] J. Lee and G.L. Fenves, Plastic-Damage Model for Cyclic Loading of Concrete Structures, Journal of Engineering Mechanics 124(8) (1998), 892-900.

[16] J. Lubliner, J. Oliver, S. Oller and E. Onate, A Plastic-Damage Model for Concrete, International Journal of Solids and Structures 25 (1989), 299-329.

[17] Bridge Explosive Loading, USAE Engineer Research and Development Center, Vicksburg, MS. 

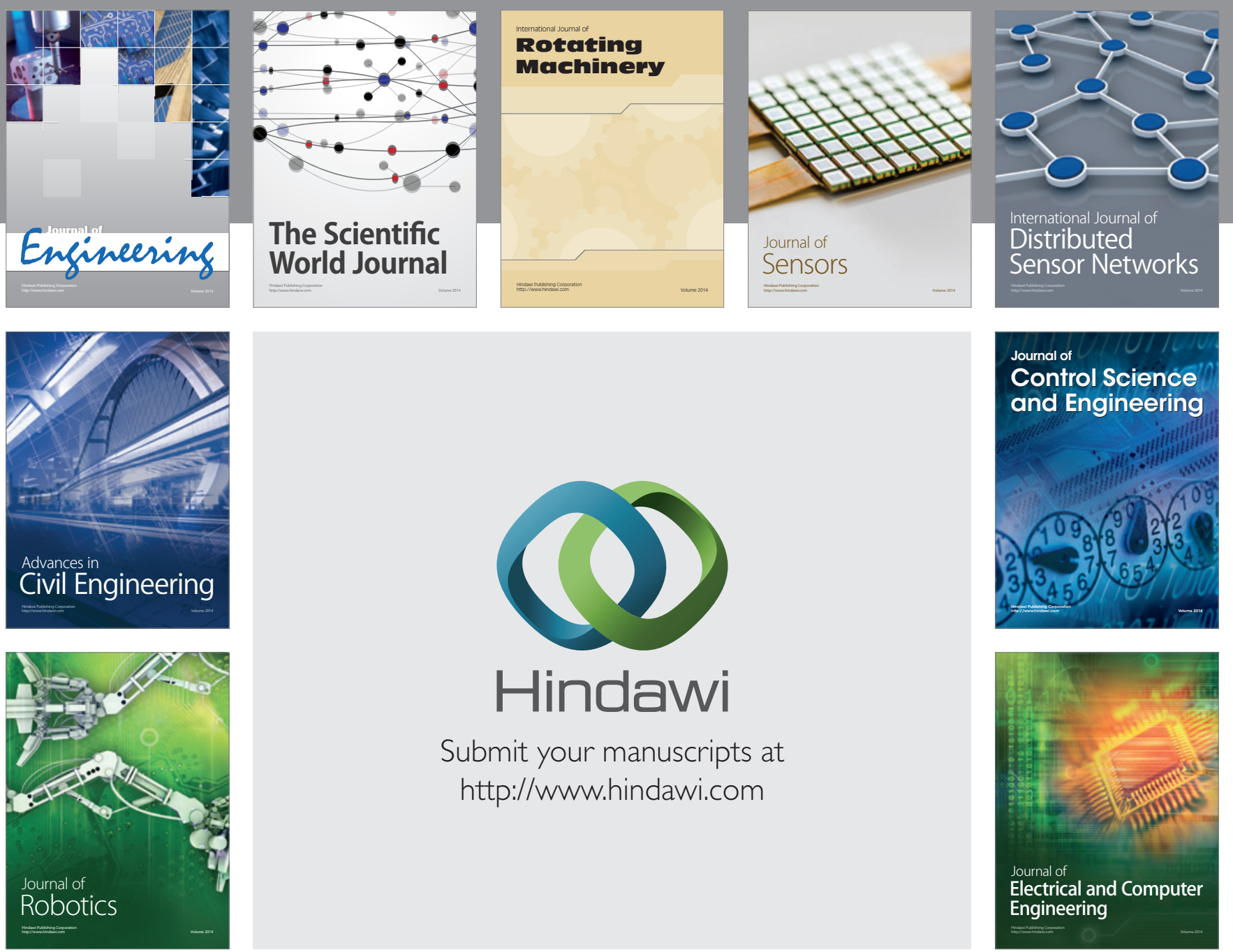

Submit your manuscripts at

http://www.hindawi.com
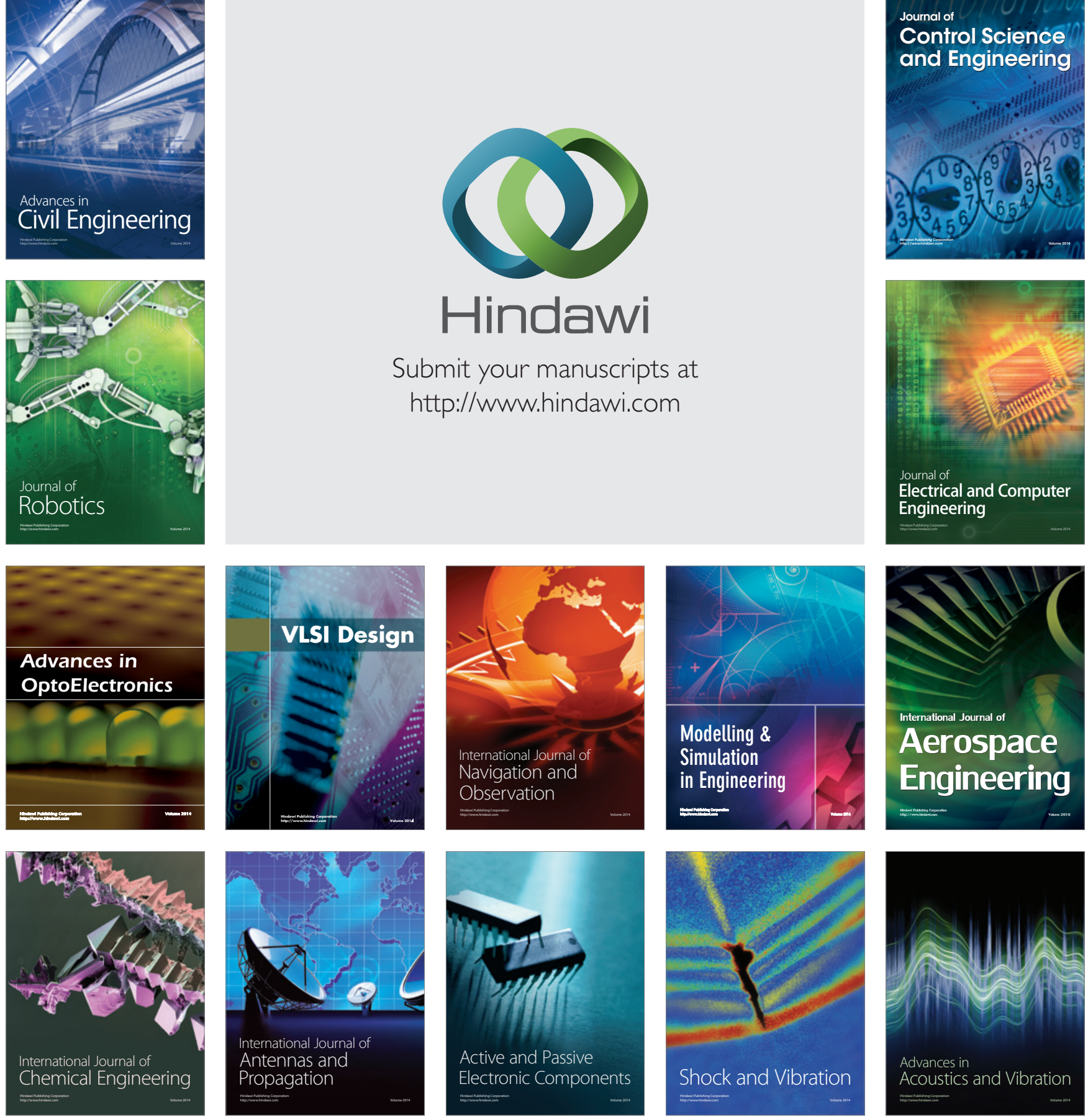